\title{
Giesinger, Johannes
}

\section{Evaluating School Choice Policies: A Response to Harry Brighouse}

formal überarbeitete Version der Originalveröffentlichung in:

formally revised edition of the original source in:

Journal of philosophy of education 43 (2009) 4, S. 589-596

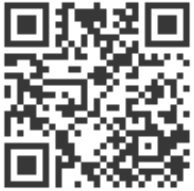

Bitte verwenden Sie in der Quellenangabe folgende URN oder DOI /

Please use the following URN or DOI for reference:

urn:nbn:de:0111-opus-42000

10.25656/01:4200

https://nbn-resolving.org/urn:nbn:de:0111-opus-42000

https://doi.org/10.25656/01:4200

\section{Nutzungsbedingungen}

Gewährt wird ein nicht exklusives, nicht übertragbares, persönliches und beschränktes Recht auf Nutzung dieses Dokuments. Dieses Dokument ist ausschließlich für den persönlichen, nicht-kommerziellen Gebrauch bestimmt. Die Nutzung stellt keine Übertragung des Eigentumsrechts an diesem Dokument dar und gilt vorbehaltlich der folgenden Einschränkungen: Auf sämtlichen Kopien dieses Dokuments müssen alle Urheberrechtshinweise und sonstigen Hinweise auf gesetzlichen Schutz beibehalten werden. Sie dürfen dieses Dokument nicht in irgendeiner Weise abändern, noch dürfen Sie dieses Dokument für öffentliche oder kommerzielle Zwecke vervielfältigen, öffentlich ausstellen, aufführen, vertreiben oder anderweitig nutzen.

Mit der Verwendung dieses Dokuments erkennen Sie die Nutzungsbedingungen an.

\section{Terms of use}

We grant a non-exclusive, non-transferable, individual and limited right to using this document.

This document is solely intended for your personal, non-commercial use. Use of this document does not include any transfer of property rights and it is conditional to the following limitations: All of the copies of this documents must retain all copyright information and other information regarding legal protection. You are not allowed to alter this document in any way, to copy it for public or commercial purposes, to exhibit the document in public, to perform, distribute or otherwise use the document in public.

By using this particular document, you accept the above-stated conditions of use.

\section{Kontakt / Contact:}

\section{peDOCS}

DIPF | Leibniz-Institut für Bildungsforschung und Bildungsinformation Informationszentrum (IZ) Bildung

E-Mail: pedocs@dipf.de

Internet: www.pedocs.de

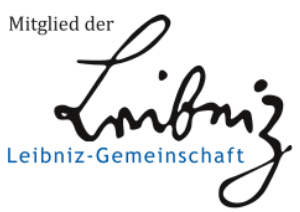




\title{
Evaluating School Choice Policies:
}

\section{A Response to Harry Brighouse}

\begin{abstract}
In his writings on school choice and educational justice, Harry Brighouse presents normative evaluations of various choice systems. This paper responds to Brighouse's claim that it is inadequate to criticise these evaluations with reference to empirical data concerning the effects of school choice.
\end{abstract}

In his book School Choice and Social Justice (2000), as well as in a recent paper (2008), Harry Brighouse evaluates different school choice policies in light of normative principles. In a response to the objections Samara Foster (2002) raises against his book, he declares that criticising his evaluations with reference to empirical data is 'beside the point' (Brighouse, 2002, p. 655). This response of his gives rise to the question of what Brighouse is actually doing when he describes some choice mechanisms as more just - or more equitable - than others. Behind this question lies another more fundamental problem; that is, what role does (moral) philosophy play in the field of education policy?

Obviously, a philosophical approach to education policy will try to outline the normative ideas or principles that should guide the decisions of policy makers. This is what Brighouse does when he argues for a principle of educational equality. But it is one thing to justify such a principle and another to answer the question 'equality of what?' Even if we manage to clarify this point, it cannot be said, of course, that everything we need for good decision making is in our hands. If we want to know whether a certain reform program should be implemented within a particular educational system, we need detailed knowledge about the status quo of this system. On this basis, we can try to figure out what will happen if the planned reform is realised. We might turn to empirical studies that evaluate similar reforms in other contexts, but it will never be possible to know in advance exactly what the effects of such a reform in our specific context will be.

As Brighouse (ibid.) explains, his aim is not to make 'empirical predictions,' and he continues by saying: 'The purpose of my discussion of actually-existing choice programmes is to isolate which features of choice programmes are likely to serve, and which are likely to inhibit justice.' This is what he is aiming to achieve in his recent article where he comments on different voucher schemes, discussing how equitable we can [590] expect each case to be. These comments are, if we believe Brighouse's earlier statements, independent of evidence gained through the empirical evaluation of existing choice schemes. This claim is evaluated 
in the second part of this paper through the conceptual framework that is outlined in the first part.

\section{Normative Principles and Empirical Conditions}

A normative assessment of school choice policies is always guided, at least implicitly, by a conception of (educational) justice. It is useful to distinguish the normative objectives that are defined by such a conception from the empirical conditions necessary to reach them.

But let us stay on the normative level, at first. Rival conceptions of educational justice propose different distributions of the good in question-education. Each conception has to clarify how this good is to be distributed among individuals, and what exactly is to be distributed; is it resources, educational opportunities, quality or quantity of education or even educational outcomes? Brighouse does not hesitate to say that education should be distributed equally, admitting that the idea of educational equality is hard to elucidate. In his current paper, he says: 'I am well aware of the variety of interpretations of equality in education, and I am going to simplify [...] by using the vague phrase 'equally good provision for each individual child' to mean equality in education' (Brighouse, 2008, p. 41). This formulation, it seems, is more focussed on the aspect of educational inputs (e.g., resources or educational quality) than on outcomes. But Brighouse considers it irrelevant, in the context of his argument on school choice, to know exactly what is to be distributed equally in the realm of education.

At least one thing, however, must be made clear - the idea of educational equality is, in Brighouse's view, not to be situated on the level of (parental) choice. It does not matter, in the first place, whether parents have equal opportunities for choice, but rather whether their children get an equally good education. Brighouse's account does not emphasize the value of choice but the principle of equality; choice is only valuable insofar as it promotes educational equality (see Brighouse, 2008, p. 49). ${ }^{1}$ To provide equal choice opportunities is, in this sense, not an objective in itself but a possible means to realise some other objective. The same should be said, I think, with regard to a principle of equal educational resources. If we would take equality of resources as an objective in itself, then at least some voucher schemes - those providing equal resources to each child and prohibiting additional investments - would guarantee the realisation of educational justice. But an equal distribution of educational resources does not ensure that each child gets an equally good education. It is not merely that some children might need more resources than others; the main point is that resources have to be made effective by schools, teachers and their students. They have to be transformed into educational quality and achievement. If we take [591] educational quality or achievement as an objective, a sufficient amount of resources is among the empirical conditions needed to reach it. 
These last remarks make use of the distinction that was mentioned at the beginning between normative objectives and empirical conditions. Empirical researchers have long tried to identify the causes of unequal educational achievement. It seems clear that such inequalities are in part caused by genetic differences and that inequalities of family background circumstances play a crucial role as well. The quality of schooling, which is determined in part by economic resources and class composition, is of utter importance too. Moreover, there is a causal link between family background circumstances on the one hand and schooling on the other, in that the parents' income and their choices determine the kind of schooling to which their children have access.

These and other empirical conditions for educational achievement work as obstacles for some children; they hinder the children from getting a good education. It is far from clearfrom a normative perspective - which of these obstacles have to be seen as illegitimate. Rival principles of justice in education give different answers to this question. One might even say that conceptions of educational justice can be distinguished according to how they answer this question. Following one of the classical approaches to equality of opportunity, for instance, inequalities of opportunity that reflect differences of natural endowment are morally acceptable, whereas inequalities resulting from social background must be seen as illegitimate. Brighouse defends similar ideas in many of his writings. In his book on school choice (2000, p. 118), he presents a principle of educational equality, stating that 'educational inequalities due to family background circumstances or family choices are unacceptable.' Brighouse's argument for this principle is based on two empirical assumptions: first, that there is a causal connection between a child's family background and the quality of schooling that is provided for her; and second, that the quality of someone's education influences his or her chances of success in competing for social rewards (e.g., income). Brighouse, depending on a notion of desert that is linked to the concept of responsibility, thinks that these rewards should be deserved. Since children did not choose their family background, says Brighouse, they do not deserve to face the educational or social disadvantages that result from it.

One problem of this argument is, as Brighouse acknowledges himself, that it does not only show the moral illegitimacy of social-but also of natural-obstacles to educational achievement. 'After all', Brighouse concedes (ibid., p. 119), 'we do not deserve our natural endowments or talents any more than we deserve our parents or the benefits they confer on us.' So, it is possible to conclude that the unequal social rewards that are caused by genetic differences are unjust. In current papers written with Adam Swift (Brighouse and Swift, 2008; 2009), he defends the classical view, also known as the meritocratic view, without referring to a justification that is based on the notions of responsibility and desert. The core idea of the meritocratic view is also present in his current paper on [592] school choice, 
where he supports the view that 'equality consists in ensuring that social class background and racial background have no impact at all on achievement' (Brighouse, 2008, p. 42). Social disadvantage is thus the primary obstacle to educational achievement that education policy should try to eliminate. ${ }^{2}$

On the one hand, it is possible to describe competing views of educational justice by clarifying which obstacles they consider as unacceptable. On the other, of course, one and the same obstacle might appear as illegitimate in very different normative contexts. This is why some education policies, which aim at eliminating or mitigating some disadvantage or other, might be justified in light of diverging principles of educational justice.The mitigation of social disadvantage, for instance, is widely accepted as a sensible aim of education policy. Similarly, those who advocate choice policies based on the view that the unequal distribution of opportunities for school choice is a serious obstacle to educational justice might not all endorse the very same principles. They do, however, share the view that school choice has the potential to eliminate some obstacles to educational opportunity or achievement that are seen as illegitimate within their view of justice. Within Brighouse's normative framework, the primary question is whether choice policies have the potential to attenuate social disadvantage within the school system.

\section{Opportunities and Probabilities}

Let us consider more closely the educational disadvantages that school choice policies are thought to mitigate. Following Brighouse, it is crucial that children are all provided with an equally good education. If we accept this as an objective, we have to ask why current education policy fails to achieve this. What obstacles prevent an equally good education from being accessible to all within the traditional system of neighbourhood schooling?

First, we have to be aware of the fact that different schools within this system are not equally good. The quality of schooling is influenced by many factors, but let us focus on the two factors already mentioned: economic resources and class composition. Within a system of neighbourhood schooling, the spatial segregation of social classes leads to a social segregation within the school system. It is well known that working-class children perform worse at school, on average, than middle-class children do. And it is often assumed that a child's educational achievement also depends on the abilities and motivation of his or her classmates. If we take this as a fact, this means that social segregation in schools imposes additional disadvantages on working-class children. The situation is even worsened, when public schools are funded by local taxes, as is the case within the U.S. school system; here, the spatial segregation along social and economic lines brings about vast inequalities of resources among schools, and these factors are likely to increase inequalities of achievement among children from different social backgrounds. 
[593] But even in countries where the schools in disadvantaged housing areas are supported with additional funds, inequalities of parental resources can amount to inequalities of schooling, since wealthy parents have the opportunity to move house or send their children to a private school if they doubt the quality of the local state school. As Brighouse points out, there is - at least in Western democracies - no educational system without choice: 'Parental choice is always operative at the margins, as long as private schools are legal: anyone with the necessary funds can exit into the private sector. And within the state/public sector, choice always has an impact' . He concludes: 'The issue is not whether we should have choice, but what kind of choice we should have' (Brighouse, 2008, p. 47).

The traditional system can be seen as unjust because it provides opportunities for choice mainly to the wealthy classes. To give equal opportunities for choice to all of the parents, though, is not an end in itself, according to Brighouse; neither is a fair distribution of resources. The issue is whether or not a particular choice system fosters an equally good educational provision for each child.

'Brighouse is extremely hopeful about the egalitarian potential of school choice serving as an instrument of social justice,' writes Samara Foster (2002, p. 302). 'Recent empirical evidence has shown exactly the opposite of what Brighouse would hope for. Evidence is mounting to confirm that choice schemes are 'making things worse' for social justice by exacerbating stratification along lines of class, race and special needs.' My aim in this paper is not to decide whether Foster's empirical assumptions are correct but to clarify the role of such assumptions within a philosophical argument about school choice. Recall Brighouse's view that empirical evidence of the kind Foster presents does not matter in the philosophical evaluation of different choice schemes. According to Brighouse (2008), we can judge progressive or targeted voucher schemes to be more equitable than unregulated programs even we do not know about the effects of such mechanisms in a particular context.

Brighouse's evaluations are, of course, highly plausible - targeted voucher schemes, for instance, that are restricted to the socially disadvantaged, provide poor families with opportunities (for choice) that they do not have in the neighbourhood system. Progressive voucher schemes take into account the fact that socially disadvantaged children usually need more educational resources than children from middle-class families. Such schemes are 'liable to be much less inequitable than other schemes, and if the vouchers are sufficiently well calibrated to the needs of the child, that will off-set worries about schools control over admissions because schools will have incentives to admit otherwise undesirable pupils, and schools stuck with otherwise undesirable pupils will be well compensated' (Brighouse, 2008 , p. 54). Discriminatory admission practices limit the opportunities of the socially disadvantaged who might not be accepted by the school of their choice. To provide them with 
additional resources is one way to mitigate this problem without preventing schools from selecting their pupils.

[594] As Brighouse makes clear, it is his aim to show that some choice schemes are more likely to promote educational equality than others. In other words, some choice schemes move us toward equality more probably or with a higher probability. In this context, it is important to distinguish the concept of probability from the concept of opportunity. Previously I mentioned that targeted or progressive voucher schemes provide disadvantaged families with more opportunities (for choice) than other systems. I did not, however, say that these schemes have a higher probability of fostering educational justice.

In many situations, giving someone the opportunity to do $\mathrm{X}$ increases the probability that she will choose to do $X$, but whether she will in fact make this choice depends on her attitudes toward $X$, her beliefs concerning $X$, as well as her preferences, values and ambitions. In the context of school choice, it is often argued that the kind of educational choices that parents make depends on their socio-economic status; middle-class parents, it is assumed, are not only more competent and better-informed choosers than working-class parents, they also have different values or ambitions concerning the education of their children. This is why, as opponents of school choice often claim, choice policies might increase social segregation within the school system. And segregation along social lines is likely to exacerbate the inequalities of educational achievement between the social classes.

Brighouse is well aware of this argument that is based on two empirical assumptions. With regard to the second assumption, he notes that segregation might not have the consequences indicated above in every possible context. Whether social segregation has to be seen as unjust, he says, depends on its effects with respect to educational equality in a particular context (see Brighouse, 2007). Concerning the first of these two assumptions, he says that it is wrong to ask whether wealthy parents are better choosers than poor parents. The crucial question is, 'whether poor parents are better choosers than the state was on their behalf in the pre-choice era. If the state chose better in the past than poorer parents do now, then we should expect a worsening of inequality; if it chose worse, than we should expect an improvement with respect to equality (and, possibly, segregation)' (Brighouse, 2008, p. 49). Brighouse is convinced that, at least in some U.S. school districts, the state 'chooses' so badly that it is virtually impossible to make a worse choice. In countries where the public system provides a good education for each child, things might be different, as Brighouse admits. He acknowledges that it is an empirical question how well parents choose in a particular context.

But he denies that the empirical quality of parental choices (as well as their further consequences in terms of a child's educational achievement) is relevant to his project of assessing different choice schemes. By describing some choice programs as more equitable than 
others, he does not refer to their effects on the distribution of educational quality or achievement but mainly to the opportunities they provide. The problem is that securing a fair distribution of opportunities for choice does not necessarily increase the probability that education (in the sense of [595] educational quality or outcomes) is distributed more equally. For instance, we cannot know with certainty that a well-designed choice system providing equal opportunities to all the families is more likely (i.e., more probable) to foster educational equality than the traditional system of neighbourhood schooling.

Imagine, though, that we had complete, detailed empirical knowledge about the consequences of different choice systems in particular contexts. In this case, I guess, Brighouse would no longer claim that empirical knowledge about the effects of different choice systems is irrelevant to their normative evaluation. As explained above, Brighouse's conception of educational justice is not situated on the level of opportunities for choice. According to his view, it is crucial to know whether a certain reform program helps to provide each child with an equally good education. The lack of opportunities for choice can work as an obstacle for some parents and children, preventing them from getting a good education, but eliminating that obstacle might clear the way for another obstacle-parental choice. By limiting his philosophical assessment of choice policies to an evaluation of the opportunities they provide, he is restricting his attention to only one empirical factor that has the potential to bring about educational inequalities.

\section{Conclusion}

So, is it 'beside the point' to criticise Brighouse's assessments of school choice policies with reference to empirical data? Without a doubt, it is inadequate to his philosophical intentions. Brighouse does not claim that those choice schemes that he judges to be more just than others necessarily bring about positive effects with respect to equality. His claim is, however, that some schemes are more likely than others to produce these effects. There are at least two interpretations of this claim. If it is read as a statement about probabilities, it runs contrary to Brighouse's own intentions. To say that some scheme brings about positive consequences with a higher probability than some other scheme is to make an empirical prediction, and this is what Brighouse refuses to do.

According to a second reading, Brighouse's evaluations are concerned not with probabilities but with the distribution of opportunities for choice. How these opportunities are distributed is part of the empirical conditions determining the distribution of educational inputs or outcomes, but in order to evaluate different policies in the light of Brighouse's egalitarian principle, it would be necessary to be informed about all of the empirical factors that determine the effects of these policies in different circumstances. An evaluation constrained to one of these factors is of limited relevance to policy makers; it is important, of course, to 
be aware of the fact that different choice schemes differ in their distribution of opportunities for choice. But when deciding whether to introduce a certain choice scheme or not, this is not enough to know. We should not give up the traditional neighbourhood system just because some well-designed [596] choice program provides better opportunities to disadvantaged families. We would only have reason to do this if we could expect it to establish a more just (or more equitable) distribution of education. In this sense, it is not beside the point to refer to empirical data in normative deliberations on school choice.

\section{NOTES}

$1 \quad$ Rob Reich (2007), on the other hand, intends to justify school choice with reference to the value of parental liberty. If parents are allowed to choose their children's education according to their own values, it seems clear that not all children will receive an equal education. Nevertheless, their education might be equally good, in a rough sense. This, at least, is what Brighouse assumes. His vague notion of educational equality is compatible with a religious, ethical, political or pedagogical pluralism within the school system.

2 But the attempt to eliminate this principle is constrained, according to Brighouse's (and Swift's) view, by two other values: the integrity of the family and concern for benefiting the less advantaged (see Brighouse and Swift 2008).

\section{REFERENCES}

Brighouse, H. (2000) School Choice and Social Justice (Oxford, Oxford University Press).

Brighouse, H. (2002) A Modest Defence of School Choice, Journal of Philosophy of Education 36.4, pp. 653-659.

Brighouse, H. (2007) Educational Justice and Socio-Economic Segregation in Schools, Journal of Philosophy of Education 41.4, pp. 575-590.

Brighouse, H. (2008) Educational Equality and the Varieties of School Choice, in: W. Feinberg and Ch. Lubienski (eds) School Choice Policies and Outcomes: Empirical and Philosophical Perspectives (Albany, SUNY Press).

Brighouse, H. and Swift A. (2008) Putting Educational Equality in its Place, Education Finance and Policy, 3.4, pp. 444-466.

Brighouse, H. and Swift A. (2009) Educational Equality versus Educational Adequacy. A Response to Anderson and Satz, Journal of Applied Philosophy, 26.2, pp. 117-128.

Foster, S. S. (2002) School Choice and Social Injustice: A Response to Harry Brighouse, Journal of Philosophy of Education, 36, pp. 291-308.

Reich, R.(2007) How and Why to Support Common Schooling and Educational Choice at Same Time, Journal of Philosophy of Education, 41.4, pp. 709-725. 
Published in: Journal of Philosophy of Education 43.4 (2009), pp. 589-596

The definitive version is available at www.blackwell-synergy.com

Correspondence:

Johannes Giesinger

St.-Georgen-Strasse 181a

CH-9011 St. Gallen

giesinger@st.gallen.ch

Personal Website: www.erziehungsphilosophie.ch 